\title{
MOBILE-WEB-BASE VOLUNTEERED GEOGRAPHIC INFORMATION APPLICATION AND GEOMETRIC ACCURACY ANALYSIS FOR TRAFFIC ACCIDENTS
}

\author{
Hacer Kübra Sevinç ${ }^{1 *}$, Ismail Rakıp Karaş ${ }^{2, a}$, Emrullah Demiral ${ }^{2}$ \\ ${ }^{1}$ Sinop University, 57000 Sinop, Turkey - kkose@ sinop.edu.tr \\ ${ }^{2}$ Dept. of Computer Engineering, Karabük University, Karabük, Turkey - ismail.karas@karabuk.edu.tr, \\ emrullahdemiral@karabuk.edu.tr
}

${ }^{a}$ Commission IV, WG IV/1

KEY WORDS: Volunteered Geographic Information, Mobile, Web Application, Crowdsource

\begin{abstract}
:
The users can contribute to geographic information through platforms such as Wikimapia and OpenStreetMap. They can also generate data by themselves with their applications in cyber worlds like Google Earth. This study is primarily designed to be a guide regarding Volunteered Geographical Information (VGI) and to evaluate the geometric accuracy of data collected from volunteers on application. The main purpose of this study is to present basic information about Volunteered Geographical Information (VGI), why users are tending to use VGI, the accuracy of the data entered by the user, to examine the examples of use in various fields, to learn about geographic information systems and to compare this phenomenon and also by developing a VGI application to examine the similarity between the actual data and the data collected from volunteer users. A mobile and web-based application have been developed to collect traffic accident data from volunteer users. The geometric accuracy analysis was performed by comparing the data collected with this application with the data obtained from the General Directorate of Security.
\end{abstract}

\section{INTRODUCTION}

As a term, Volunteered Geographic Information (VGI) defines the creation of spatial data by a great number of citizens, who mostly do not have any formal training in this field (Goodchild, 2007). When VGI is examined as a term, it includes collaborative maps, crowdsourcing, user-generated content, collective intelligence, and geotagging.

Obtaining data for GIS is the most troublesome, timeconsuming, and expensive stage. For this reason, instead of collecting first-hand the data needed by a GIS, making use of the existing data is a more rational method (Karaş, 2001). In this respect, taking the data from the user provides a great profit in terms of price/performance for GIS.

When traffic accident statistics are examined, the first cause of accidents is driver mistakes, which include not complying the vehicle speed with the conditions required by the road, the air and the traffic. The following questions constitute the main titles of the present study: "What can be done about preventing traffic accidents? How measures can be taken to prevent traffic accidents with Geographic Information Systems?

\section{MATERIAL AND METHODS}

\subsection{System Architecture}

The operation of this system is shown in Figure 1. The system consists of mobile and web application interfaces. Volunteering users can access the system at TezKaza.site web address or download TezKaza mobile application. The user saves historical information and land accident points to the system with the map or marks the spot as the accident point on the page that opens. The system is recording these data. System administrators can view these data on the map from the TezKaza web application. Also, system administrators can view the recorded accident data obtained from the General Directorate of Security between 2013 and 2015 on the map.

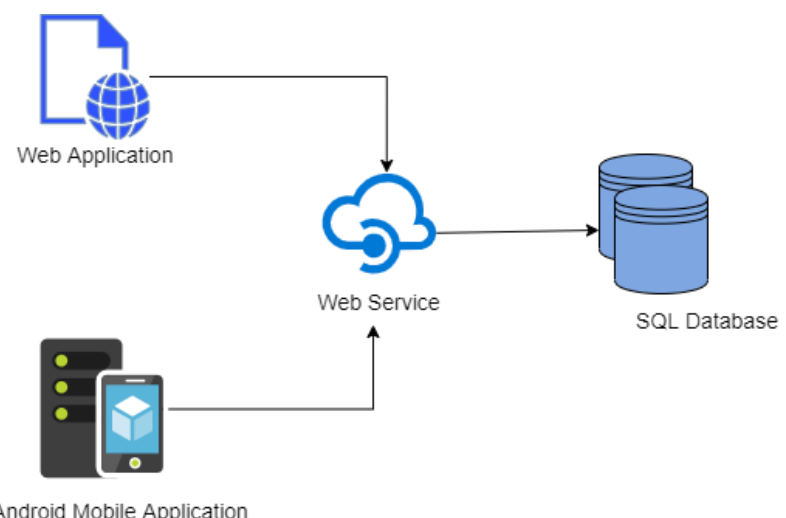

Figure 1. System Architecture

The web application constitutes the presentation layer in background operations (Figure 2). Google Maps Api and JavaScript are running at the presentation layer. The user enters the data on the map with Google Maps Api and JavaScript. The application initiates communication with the web service, which transfers the data to the business layer in the application, and communicates with the Database. The Business Layer initiates communication with stored procedures, and saves the data to the database.

\footnotetext{
* Corresponding author
} 


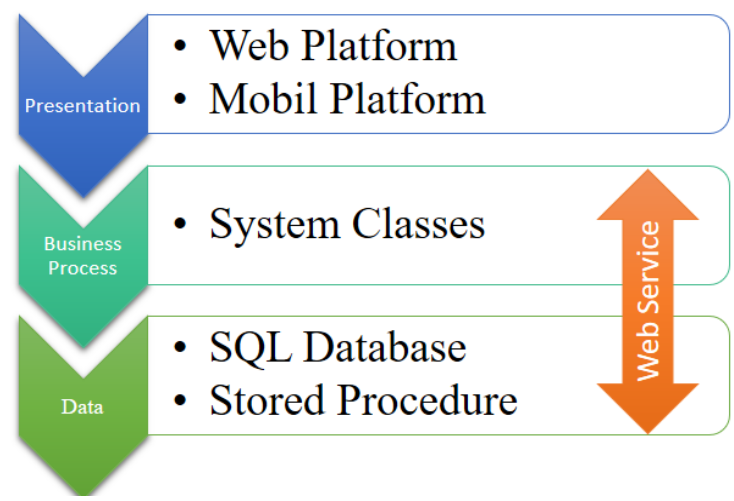

Figure 2. System background architecture

\subsection{Web Application}

The web interface application is prepared with C\# Asp.NET web programming language. The Google Maps was used together with JavaScript API as footing at the Web application page. The necessary window is created to fill the data with JavaScript.

As shown in Figure 3, the data received with JavaScript is sent to the web service when the user enters the data and clicks on the save button. Here, the reason why web service is used is because the platforms are different. The data are saved from a platform using JavaScript to SQL Server over Asp.NET. Right at this point, it is the web service that will provide the communication between.

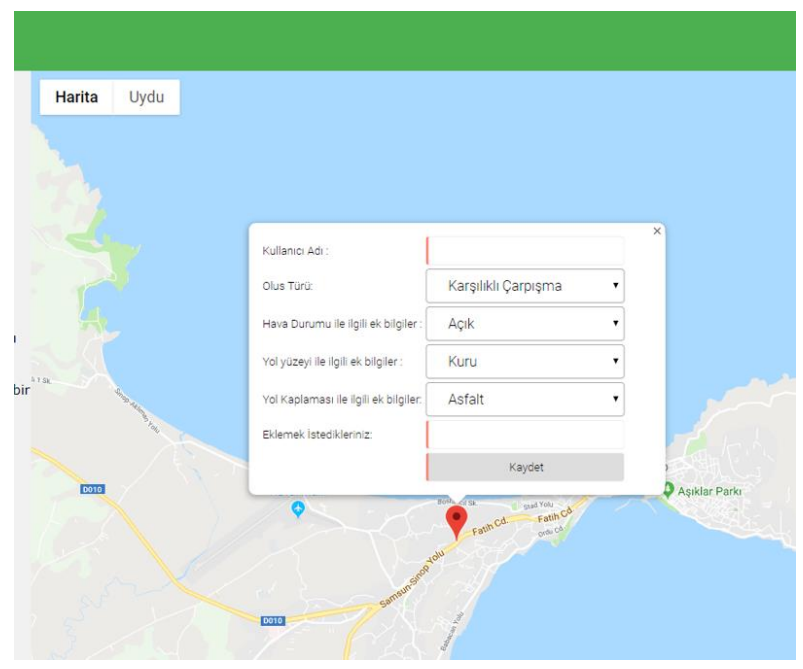

Figure 3. Data entry screen

The screens that the administrator can view after entry are given in Figures 4 and 5.

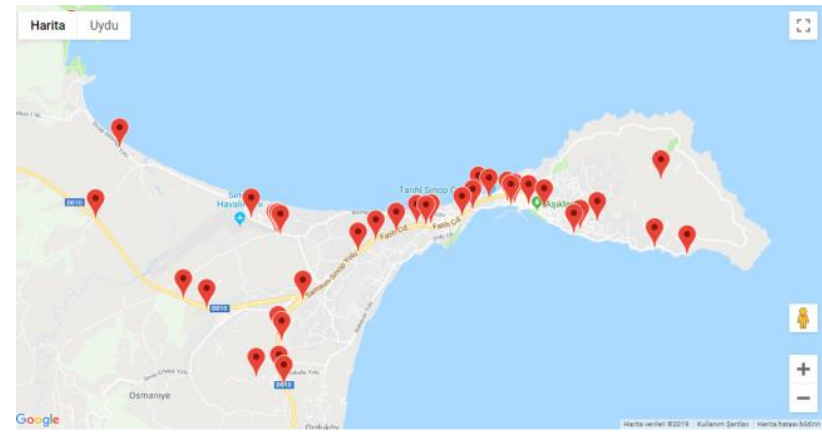

Figure 4. Displaying the data entered by the user on the map.

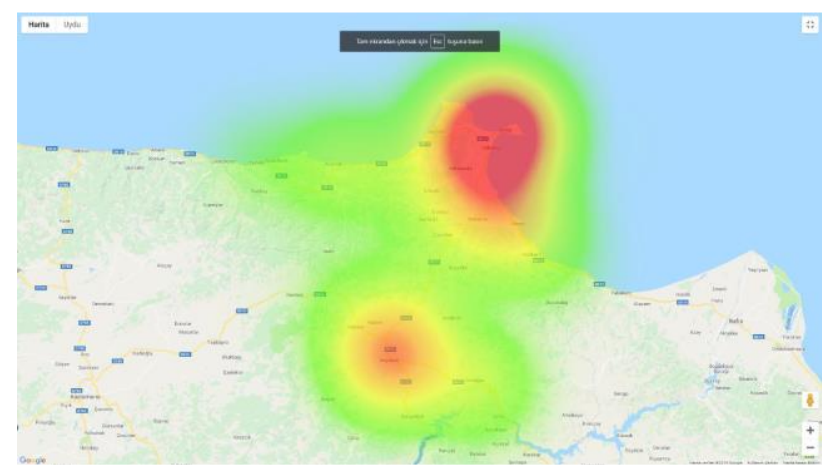

Figure 5. Displaying the actual accident data on the heat map.

The blue pointers show the actual accident data, and the red pointers show the accident data entered by users in Figure 6 . Also, a small information window is opened when these pointers are clicked on.

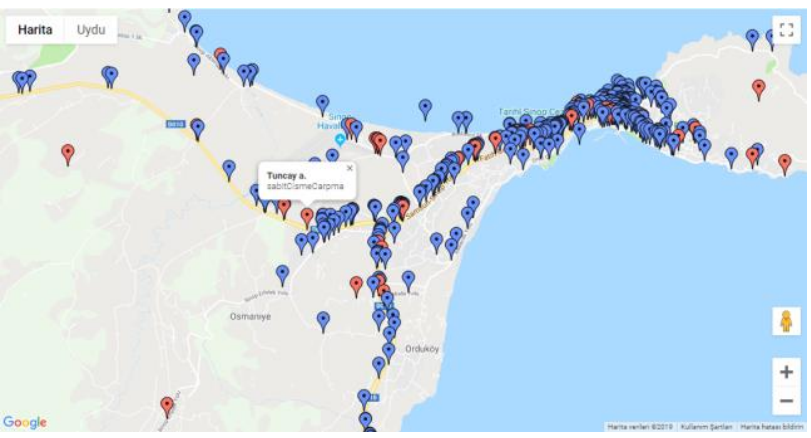

Figure 6. Displaying the actual data and user-entered data on the same map.

\subsection{Mobile Application}

The mobile app is developed in an Android-based way. When the application is opened, the initial screen comes with the app logo for 1.2 seconds, and then switches to the map interface on which the user marks his/her position, and presses the "Select the Location I marked" button, and is then transferred to the Information interface.

As the app moves to the Information Interface from the Map Interface, the latitude and longitude data of the user's chosen location are also transferred. On the Information Interface, there are data that the user must enter. The user can log in with any user name. The purpose here is not to keep users registered, but 
to obtain information for data entry. There are areas where the user can enter information about the accident, such as weather conditions at the time of the accident, road conditions (dry, wet, snowy, etc.), information about road coating, and other information s/he wants to add (Figure 7).

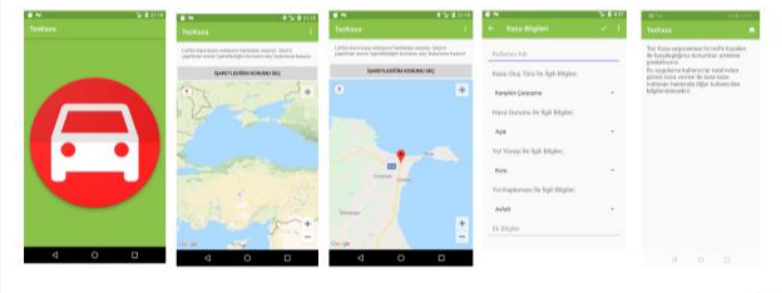

Figure 7. Mobile application interfaces.

\subsection{Geographic Data Quality}

To evaluate the quality of the spatial data collected by this study, it is necessary to apply quality control methods in the geographic database (Girres \& Touya, 2010) According to the ISO Geographic Information Quality Principles;

- Geometric accuracy

- Attribute accuracy

- Completeness

- Logical consistency

- Semantic accuracy

- Currentness

- Usage

The data collected in this study are examined only in terms of geometric accuracy. One of the purposes of the thesis is that it was based on the hypothesis that the geometric accuracy of the collected data will be close to each other.

Geometric accuracy in the GIS is the compliance degree if the information on a map to the real-world values. It is a matter of the quality of the data collected and the number of mistakes found in the dataset or the map (Santini, 2019). The geometric accuracy of the data collected with the TezKaza application will be calculated by comparing them with the actual accident data obtained from the General Directorate of Security. A web form has been prepared on the Web application to make comparisons. For point comparisons, the actual data have the latitude and longitude information on the "XCoordinate" and "YCoordinate" columns in the database. The voluntary data are in the "knm_latitude" and "knm_longitude" columns. The shortest distance is found by comparing each node obtained from volunteers and the actual data individually. In the literature, the Euclid Distance or Haversine Formula are used for this comparison. In this study, the Haversine Formula was preferred.

$$
\begin{gathered}
a=\sin 2(\Delta \varphi 2)+\cos \varphi 1 * \cos \varphi 2 * \sin 2(\Delta \lambda 2) \\
c=2 * \operatorname{atan} 2(\sqrt{ } a), \sqrt{ }(1-a) \\
d=R * c
\end{gathered}
$$

where $\varphi=$ latitude

$\lambda=$ longitude

$\mathrm{R}=$ radius of the earth

atan $2=$ arctangent value (taken as $6371 \mathrm{~km}$ here)

The Haversine Formula shown in Equality 1 is used to calculate any distance between two different locations on the Earth's surface (Movable Type Scripts, 2019).
The maximum, minimum distance, mean, standard deviation, and coefficient of variation are calculated in the evaluation interface (Figure 8). The geometric accuracy is focused according to the calculated values.

\begin{tabular}{l|l|} 
Maximum Distance & 16,012 \\
\cline { 2 - 2 } Minimum Distance & 0,036 \\
\hline Mean & 0,101210144927536 \\
\hline Standard Deviation & 0,0638785061219732 \\
\hline Coefficient of Variation & $\$ 63,1148055046345$ \\
\hline Total Actual Data Count & 1027 \\
\hline Total Voluntary Data Count & 139 \\
\hline
\end{tabular}

Figure 8. Evaluation interface

\section{CONCLUSIONS}

Geometric accuracy can be calculated with the actual data from 2013-2015 and data obtained from users. It constitutes $13 \%$ of the total data count. Having over $10 \%$ data for the sampling is adequate for this study. The coefficient of variation percentage is calculated with the nearest distances of nodes entered by volunteer users to actual nodes.

As shown in Figure 8, the calculated values are calculated in kilometers. While the maximum distance is $16.012 \mathrm{~km}$, the nearest distance is $0.036 \mathrm{~km}$. The coefficient of variation was approximately $63 \%$. There is about $63 \%$ similarity between the data entered by volunteer users and the actual data.

\section{RECOMMENDATIONS}

The Smart Cities concept is now a requirement. Because of the fact that technology is at the reach of each individual, the need for intelligent systems is increasing with each passing day. This study, which is in the Smart Cities concept, can be used in areas with traffic density. In further studies, a system that produced a warning can be developed as the land nears the crash point according to the accident data entered by users.

\section{ACKNOWLEDGEMENTS}

This study has been supported by BAP Unit of Karabuk University (Project No: KBÜBAP-18-YL-013). We are indebted to their supports.

\section{REFERENCES}

Girres, J. F., \& Touya, G. (2010). Quality Assessment of the French: OpenStreetMap Dataset. Transactions in GIS, 435-459.

Goodchild, M. (2007). Citizen as sensors: The world of volunteered geography. GeoJournal, 211-221.

Karaş, İ. R. (2001): Coğrafi Bilgi Sistemlerine Yönelik İnternet Uygulamaları ve Yazılım Geliştirme. Gebze: Gebze Yüksek Teknoloji Enstitüsü.

Movable Type Scripts. (2019, May1s). Calculate distance, bearing and more between Latitude/Longitude points. Movable Type Scripts: http://www.movabletype.co.uk/scripts/latlong.html 
The International Archives of the Photogrammetry, Remote Sensing and Spatial Information Sciences, Volume XLIV-4/W3-2020, 2020 5th International Conference on Smart City Applications, 7-8 October 2020, Virtual Safranbolu, Turkey (online)

Santini, R. A. (2019, May1s). Lesson 7 - Understanding GIS Error, Accuracy, and Precision, and Metadata. Energy Industry Applications of GIS: https://www.eeducation.psu.edu/geog469/book/export/html/252

\section{APPENDIX}

We would like to thank Sinop University and General Directorate of Security for supporting us with the data collection. 